\title{
Más allá del análisis de la pobreza: narrativas desatendidas en el pensamiento marxista. Comentario a la ponencia central de José Paulo Netto
}

\author{
Beyond poverty analyses: unheard narratives in \\ Marxist thought. Comment to José Paulo Netto's \\ central conference
}

\section{PhD. Lena Dominelli}

Lena Dominelli, es profesora de la School of Applied Social Sciences de Durham University y miembro de Academy of Learned Societies for Social Sciences 1.32 Old Elvet Durham,DH1 3HN; lena.dominelli@durham.ac.uk

\begin{abstract}
Resumen
Los relatos dan cuenta de experiencias de vida. Con frecuencia éstos se subestiman o se pasan por alto, si bien son importantísimas herramientas en la capacidad del trabajador social para interactuar en forma efectiva con los usuarios de los servicio sociales y escucharlos relatar sus propias historias de vida desde sus propios puntos de vista. Utilizaré técnicas narrativas para responder a la ponencia del Profesor Netto, y para ello utilizaré dos historias. Una de esas historias habla de invisibilidad; la otra habla acerca del amplio espectro de voces que necesitan ser escuchadas si es que nos proponemos resolver los persistentes problemas sociales como la pobreza en el mundo, un objetivo que encarna lo medular de la presentación del Profesor Netto.
\end{abstract}

Palabras claves: (Narrativas, invisibilidad, empoderamiento)

\begin{abstract}
Narratives are accounts of life experiences. These are often undervalued and neglected, although they are crucial tools in a social worker's capacity to interact effectively with service users and listen to them tell their life stories from their points of view. I will use narrative techniques to respond to Professor Netto's paper and draw upon two stories to do so. One of these is a story about invisibility; the other about the wide range of voices that need to be heard if we are to resolve intractable social problems like world poverty, an objective that forms the crux of Professor Netto's presentation.
\end{abstract}

Key words: (Narratives, invisibility, empowerment)

\section{Jugadores invisibles: vistos sin ser escuchados; escuchados sin ser vistos}

Mi primera historia habla de participantes invisibles, en particular mujeres, y sobre los sesgos de género, clase social y raza en las relaciones sociales que imponen desventajas en sus vidas cotidianas e incluso en las rutinas de la academia. Utilizo un relato biográfico para plantear mis puntos. Lo hago en el contexto del reconocimiento de que para mí es un privilegio exponer ante un público de personas tan distinguidas entre sus participantes y organizadores.

Primer relato: una alegoría

Comienzo esta alegoría conmigo caminando por un hermoso bosque de hayas en Inglaterra, llevando mi famosa mochila, cuando pienso en sentarme bajo los frondosos árboles a la brillante luz del sol para redactar mi ponencia. Pero, ¿dónde estaba ésta? 
Busco por arriba y por debajo, gritando hacia los desiertos bosques, ‘¿Dónde está mi ponencia? ¿Dónde está mi ponencia?' Corro desesperadamente hacia delante y hacia atrás sin estrategia ni plan, le pido frenéticamente y sin éxito a las sombras que hagan aparecer mi ponencia, y en eso me veo a mi misma ante un extraño edificio de donde sale un funcionario elegantemente vestido. Pienso que podría saber algo y me acerco a ese hombre cuyos brillantes botones en su uniforme resplandecen al sol. 'Permítame revisar su bolso', me dice con brusquedad. 'No le está permitido pasar la frontera con material subversivo. Tomaré su lápiz labial, señora. Eso también está prohibido. Ahora, entrégueme su ponencia. Debe entregarme su ponencia, insisto'. El hombre se niega a creerme cuando le digo que no tengo ninguna ponencia para entregarle. Decide que yo estaba siendo intransigente, de modo que me lleva hacia otro edificio en donde hay un letrero que dice 'se habla español', sin aceptar mi versión de que no hablaba ese idioma. Entonces soy llevada a la aduana chilena en donde el primer funcionario le dice a otro hombre uniformado, 'Esta mujer se niega a entregarme su ponencia, está comportándose con terquedad, de modo que tendremos que disciplinarla. La llevaré a la otra oficina".

Me lleva por un pasillo oscuro y angosto en donde comienzo a gritar. '¡Suéltenme!, ¡Suéltenme! Aquí abajo hay demasiado humo'. Por un instante logro escapar y corro hacia una ventana abierta cuando el hombre coge mi mano y la tuerce tras mi espalda. Entonces desperté. Era lunes por la mañana y yo estaba en una cama en el hotel Crowne Plaza. Solté un suspiro de alivio. Era un mal sueño, ¿o tal vez debiera decir pesadilla? Y ahí, asomada bajo la puerta, estaba la ponencia -ien portugués!

Los invito a explorar el carácter sexuado en este relato. Es variado y complejo. Debido a las limitaciones de tiempo, debo avanzar hacia el segundo relato.

\section{Segundo relato: las desigualdades complican la teoria, la práctica y las acciones}

Este relato se basa en la ponencia que acabamos de oír. En ella exploro la paradoja de las crecientes desigualdades en el crecimiento. El Profesor Netto se centró en un tema clave: la inequidad expresada en términos de pobreza, y nos ofreció impactantes estadísticas que hay que dejar en claro. No podemos negar la persistente y penetrante existencia de este flagelo en el mundo. No los detendré con un ensayo acerca de las muchas cifras que aparecen en la presentación del Profesor Netto. Pero sí quisiera decirles que, para mí, la pobreza y la desigualdad tienen el rostro de una mujer o de un niño. Y ésta deteriora sus vidas en formas muy específicas que varían según su género, 'raza', edad y otras divisiones sociales que incluyen las clases sociales, las discapacidades y la orientación sexual. El Profesor Netto se refirió principalmente a lo que respecta a clases sociales, no obstante, se puede hacer más de un relato sobre la pobreza si es que van a abordarse en forma adecuada las complejidades existentes en la experiencia humana de la pobreza y la exclusión social; puesto que si éstas no se consideran, los relatos acerca de la pobreza se vuelven muy parciales y excluyen a aquellos que sufren los efectos de la pobreza al acallar sus voces y condenar sus experiencias a la invisibilidad.

Si bien concuerdo con la tesis básica del Profesor Netto de que la globalización y el neoliberalismo en la economía son los terribles gemelos que apuntalan las penurias contemporáneas, quisiera ir más allá de este fenómeno para afirmar que la forma de globalización que se conoce como neoliberalismo ha invadido las rutinas de la vida cotidiana llegando a transformar lo que yo llamo prácticas de la vida cotidiana (ELP) $)^{33}$ y a reconfigurar una crisis en las relaciones sociales de acumulación capitalistas convirtiéndola en una crisis del estado de bienestar, poniendo a su vez a la profesión del trabajo social en medio de esta contradictoria situación. En esta situación se le pide a la profesión que: proporcione capital a los empresarios privados al contar con servicios destinados a satisfacer las necesidades de los individuos, familias y comunidades privatizados; y que actúe como policía de los grupos marginados u oprimidos al echar a andar un molino que hace girar las ruedas del riesgo y la falta de seguridad a fin de asegurar su conformidad en medio de precarias circunstancias que no son dignas de llamarse lugares en los que viven personas. Y aún así, se les pide que se ganen la vida a duras penas en esos espacios.

Mientras tanto, los ricos recorren el mundo en una incesante búsqueda de nuevos mercados y productos, dejando tras sí, un rastro de destrucción del medioambiente, sin conciencia ni de esto, ni de las desigualdades que co-existen con aquello, y que sirven de sostén a sus espléndidos estilos de vida. Llevan vidas afortunadas, con libertad de atravesar fronteras sin barreras mientras el dinero siga tinti-

2 ELP-Everyday life practices o prácticas de la vida cotidiana. 
neando en sus bolsillos. Sus actividades enfrentan pocos controles y no deben someterse a dar cuenta de sus devastadoras decisiones. Las personas pobres no generan la degradación ambiental provocada por los procesos productivos industriales que priorizan el lucro por sobre las personas, y originan masivas emisiones de gases que contribuyen al efecto invernadero. Pero son ellas quienes sufren lo peor de sus desastrosos resultados, tal como lo demostraron el huracán Katrina en Estados Unidos y los desastres tanto naturales como provocados por el hombre (utilizo esta expresión en forma deliberada) en Bhopal, en la India.

Este es un problema de clases, para estar seguros. Pero en occidente, la palabra 'clase' se ha vuelto un tabú. Nadie la menciona. Está tan arraigada en las prácticas cotidianas que se ha vuelto invisible. Hablaré de un ejemplo común que podrá resultarle familiar a aquellos de ustedes que hayan viajado en avión. Originaré la historia en mi propia biografía. Mi primer viaje en avión ocurrió en 1967. Por entonces no había distinciones de clase. Los asientos y alimentos eran los mismos para todos. Todos ocupábamos asientos suficientemente amplios como para estar cómodos y con espacio suficiente para estirar las piernas. Se nos ofrecían alimentos de verdad en vajilla de porcelana de verdad y con cubiertos de verdad. Ahora, permitan que regrese a un viaje reciente en mi aerolínea favorita. Ésta acababa de introducir cuatro clases en sus vuelos para recorridos largos. Estas son, en orden descendiente: Primera clase, con servicio, asientos y alimentos privilegiados; Clase ejecutiva; Clase turista superior; y Clase para el ganado (sólo que la llaman clase económica).

En la clase para el ganado, se supone que uno está tan agradecido por el viaje que se espera que siendo adulto uno se retuerza para caber en un asiento de tamaño infantil, consuma pésimos alimentos servidos en bandejas de plástico y con cubiertos plásticos. Se dice que le sale más costoso a una aerolínea el transporte de una persona en clase para ganado que en Primera Clase. Pero como soy cientista social realicé mi propia investigación y conté la cantidad de asientos de clase para el ganado que cabrían en el espacio destinado a un pasajero de Primera clase y descubrí que dependiendo del tipo del avión la relación que había entre primera clase y clase ganado variaba entre 4 a 1 y 6 a 1 . De modo que los pobres siguen subsidiando a los ricos. Esta investigación es, por supuesto, anecdótica. No pedí autorización para medir el espacio con una huincha de medir, así que confié en las antiguas medidas inglesas - una pulgada tiene la longitud que existe entre la punta del dedo pulgar hasta la primera falange; el largo de un brazo es una yarda. Estas desigualdades han entrado con sigilo y han sido aceptadas como la regla. Tanto es así, que ni siquiera se habla acerca de estos temas. Sin embargo en la clase para el ganado las personas pueden quejarse por no tener suficiente espacio para estirar las piernas, para caber en los asientos, o en caso de tener alguna discapacidad, para la silla de ruedas. Y todo esto sin hablar de las penurias que imponen sobre ellos las preocupaciones relacionadas con los riesgos de seguridad más elevados y de los perfiles étnicos que comenzaron con la "Guerra al Terrorismo". De modo que, cuando los marxistas le dicen a usted que la clase importa, créales. Las prácticas cotidianas les dan la razón, aún cuando se trate de experiencias de género, de raza o de clase.

Las prácticas cotidianas son importantes para los trabajadores sociales debido a que su reacción ante el impacto de éstas sobre las personas los convierte ya sea en parte del problema o en parte de la solución. Los trabajadores sociales pueden avalar la complacencia de la sociedad postmoderna o pueden tomar conciencia de la forma en que las complejas relaciones sociales reproducen y dan estructura a las desigualdades mediante rutinas cotidianas que se dan por sentadas y actuar a favor de potenciar a sus clientes en la toma de decisiones liberadoras y de respaldar su movilización destinada a obtener los recursos y las capacidades para tomar decisiones que les han sido negados mediante la promulgación de relaciones sociales de desigualdad.

El Estado es también un participante clave en el fomento de relaciones neoliberales. Lo hace al aprobar legislación y al poner a disposición de la acumulación privada los recursos públicos mediante el subsidio a los impuestos, garantías y otras formas de traspaso. Y otra vez, sus intervenciones tienen diferente configuración para mujeres, niños y hombres. De este modo, las complejidades de la vida han de ser tomadas en cuenta si sus experiencias y conocimientos van a usarse para transformar la vida social llevándola en una dirección más equitativa. El uso de la violencia es monopolizado por el Estado y por los traficantes de armas que las comercializan para trastornar la vida cotidiana de las masas de habitantes de la tierra a pesar de sus derechos ciudadanos. Esto protege los intereses de aquellos que tienen dinero en lugar de proteger a las personas socialmente excluidas que claman imperiosamente por su inclusión, tal como el relato de la historia 
de Santa María de Iquique nos dejó en claro la noche anterior. Al mismo tiempo, la preocupación de la Presidenta Bachelet por mejorar las vidas de las personas comunes y corrientes demuestra que el Estado puede utilizarse para fomentar el bienestar, si bien para tener éxito ella necesitará de una enorme cantidad de recursos y del considerable respaldo del pueblo y además tener de su parte a los formadores de opinión al igual que a aquellos con el poder de imponer sus propios intereses privados por sobre la vida pública. Espero que lo consiga.

Mientras tanto, aquellos que cuentan con extensos recursos tienen una cantidad de respuestas a su disposición. Pueden aceptar las desigualdades, acomodarlas con cambios menores, o rechazarlas a favor de transformar las relaciones sociales. Hay quienes se sienten culpables de ser ricos. Bill Gates es ejemplo de una de estar personas. Les pide a otros que se le unan en obras filantrópicas, pero deja intacto al sistema. Esto tiene relevancia particular en su esfuerzo por abordar la crisis del SIDA/VIH proporcionando medicinas para aquellos que están enfermos. No discutiré que esto se haga, dado que son tantas las personas cuyas vidas penden de un hilo. Sin embargo, al pagar por las medicinas, se soslaya el problema de cuán lejos pueden llegar las corporaciones multinacionales en la protección de sus márgenes de beneficios y éstas siguen adelante cobrando elevados precios por recursos que por lo general se desarrollan mediante trabajo en equipo y con frecuencia implican apoyo no reconocido por parte del Estado, aún cuando éste venga en la forma de subsidios de fondos públicos que promueven la investigación o la reducción de los impuestos. La respuesta de Gates también favorece al consumidor homogéneo, que comercializa materias primas -el que puede pagar por lo mejor consigue lo mejor. Los demás deben arreglárselas con lo que obtengan. Muy parecido a lo que lo que quienes viajan en clase ganado pueden hacer en un avión.
Con frecuencia los trabajadores sociales son atraídos y tienen una larga tradición involucrándose en actividades filantrópicas. Quienes practican la filantropía a través del trabajo social han fracasado en abordar las inequidades estructurales. Los demandantes de la clase obrera atendidos por mujeres blancas de la clase media son frecuentemente tratados en forma moralmente condescendiente cuando éstas se proponen enseñarles "a comportarse adecuadamente" según las normas de la clase media. Los trabajadores sociales pueden elegir la forma de relacionarse con los clientes. Esta forma no tiene por qué ser abusiva ni tampoco tiene que mantener el status quo. Sin embargo, al cuestionar este estado de cosas, deberían además estar concientes de que se están arriesgando, lo que puede incluir incluso hasta el poner en riesgo sus vidas, tal como lo han demostrado muchos trabajadores sociales en Chile que se cuentan entre los "desaparecidos".

Los trabajadores sociales pueden desarrollar nuevas perspectivas de la sociedad al entender, teorizar y reflexionar de manera crítica sobre la forma en que el neoliberalismo impacta en las vidas cotidianas de sus clientes. Pero no basta con sólo pensar acerca de ello. Se debe actuar. No puede evitarse la acción si han de transformarse las relaciones sociales y el neoliberalismo. Esto implicará una lucha que es global en su magnitud, puesto que la globalización ha penetrado cada área del globo y ha reunido a las personas en destinos que están entrelazados e interconectados. Pero los trabajadores sociales no pueden por sí mismos cambiar el mundo. Deben formar alianzas que se construyen en torno a círculos de resistencia en donde imaginan un mundo en el cual todos prosperarán. Las alianzas de resistencia promueven la solidaridad y la acción colectiva basada en la reciprocidad, en los derechos humanos y en la justicia social. Al hacer mejores las vidas de otros el trabajador social se transforma a sí mismo y puede dejar de ser un patito feo para convertirse en un bello cisne. 